\title{
The Effect of Reputation to the Moral Hazard in C2C E-Market with Game Theory
}

\author{
Fangjun Mu \\ Management School, Jinan University, Guangzhou, China \\ Email: 784558439@qq.com
}

Received 23 July 2015; accepted 25 August 2015; published 28 August 2015

Copyright (C) 2015 by author and Scientific Research Publishing Inc.

This work is licensed under the Creative Commons Attribution International License (CC BY). http://creativecommons.org/licenses/by/4.0/

(c) (†) Open Access

\begin{abstract}
It is well known that the reputation is the basis of a seller to survive and gain trust from customers in a competitive business environment. But as the existence of information asymmetry between buyer and seller, the moral hazard problem is the key obstacle that impedes the benefits of related shareholders and reduces the efficiency of total market. It is crucial to design a control mechanism to avoid the negative impact of moral hazard. This paper studies the principal and agent relationship between buyer and seller in C2C e-market; because of the influence of information asymmetry, many customers suffered from being cheated by sellers with defective products in practice. These frequent cases will deteriorate long term relationship between sellers and buyers. Here we focus on the analysis of the causes of moral risks and the effect of reputation on oral risk with repeated game theory. The purpose of this paper is to help both firms and customers effectively avoid morality risk and realize a win-win situation.
\end{abstract}

\section{Keywords}

\section{C2C E-Commerce, Moral Hazard, Reputation Model, Game Theory}

\section{Introduction}

C2C e-commerce plays an indispensable role in the Electronic Commerce market in China and the total transaction value is estimated to be 607 billion in 2014 [1]. But there is one serious problem impeding the development of $\mathrm{C} 2 \mathrm{C}$ e-commerce for long time, that is the trustiness between strangers. There are many factors that influence the relationship between the seller and the buyer in C2C e-market. One of them is moral hazard, which means all egoistic behaviors of seller after making a deal with the buyer. This problem originally raised from insurance industry, where individual is easily to depend on the seller, as the buyer usually lacks the sense of taking some precautionary measures. In C2C e-business, the seller who will adulterate and do deliberate bribery is the reflec- 
tion of moral hazard. The underlying reason of moral hazard is information asymmetry, which means the seller has more information about the quality, cost of product, while customer knows less. In the practice of C2C e-commerce, the seller usually will take an advantage of the quality of product, costs, and transportation costs and so on over customer. It is depicted that there are two types of information asymmetry depending on when and why it exists. One is adverse selection which happened before the coalition between buyer and seller, the other is moral hazard which happened after the deal.

In this paper, we will focus on the problem of moral hazard between the seller and buyer in C2C market and potentially intend to help solving the problem. One popular way is to introduce reputation to track the past behavior of seller [2]. A corporate reputation is an overall evaluation that reflects the extent to which people see the firm was substantially "good" or "bad" [3]. A good reputation is valuable because it can enhance trust and confidence so that the buyer feels that "it is safe to buy products and service from this seller". This outcome can also benefit the seller in its markets and various researches have also shown that sellers with good reputation are better able to attain and sustain superior profits outcomes over time.

Our primary research question is how the expected profits of the seller and the buyer depend on these two factors, one is the type of the seller, and the other is the reputation of the seller from the buyer. For example, does the seller always benefit from cheating or not. To answer this research question, we will examine a market where the reputation mechanism exists and check the influential mechanism. In this paper, we will set the reputation model of the seller in C2C E-Commerce market. We first characterize the situation that the type of seller is not common knowledge and then demonstrate that even though cheating has a direct benefit to the seller, it can sometimes hurt the seller, buyer, or both if the deal goes in the long run. Furthermore, we show the impact of reputation. In addition, we illustrate that the seller will always choose to be honest when the mechanism of reputation works. In a typical game-theoretic view of the relationship between buyer and seller, each player acts in order to maximize its own profit (rational player) without taking into account the overall optimal. Thus, incentive is offered to influence the behavior of the other one. Such an incentive is reputation.

This paper proceeds as follows: In Section 2 we review related literature. We then present the model in Section 3. We analyze the model to explain the existence of moral hazard and the coordination mechanism of reputation respectively in Section 4. Finally, we discuss extensions of our paper and provide our concluding remarks in Section 5.

\section{Literature Review}

C2C e-commerce specifies all business activities related to all buyer and buyer, like e-bay and TaoBao. There are many advantages like lower price, better service of $\mathrm{C} 2 \mathrm{C}$ e-commerce, the main difference between $\mathrm{C} 2 \mathrm{C}$ e-commerce is that the relationship between the seller and the buyer could be switched. The possibility of the occurring of lemon market means the reputation is also one aspectneed to be considered.

As a potential motivation, reputation could inspire seller to increase service quality. Since Adam Smith, reputation has been regarded as a very important mechanism to guarantee the implementation of contract in Economics [4], but it is widely used just since the combination with game theory. In management practice, the motivation of reputation is also very popular and has brought new management thinking to create and maintain a good reputation. For example, Kleps discussed that the company is a carrier of reputation, power origins from reputation, which determines endogeneity. But his argument is limited to B2B market. Here we are more focusing on the trade between customer and customer in e-commerce market, to discover the reputation mechanism is a bilateral problem.

The earlier research about reputation comes from economic, which emphasized the constraint of the agency market to the behavior of agency. As they are living in a competitive market, the potential value of the agency is determined by his past performance. The agency who cares about his reputation will be responsible for his behavior even there is no explicit motivational contract, they would work hard to increase the level of reputation, hoping they will gain more in the future.

Later researchers started to connect the reputation and the incentives of seller to build a complete model [5]. It is said the reputation of the market could be used as a replacement of explicit contract. When both parties in the game only cares about the immediate benefits, the optimal strategy is to not return debt, the optimal action for the bank is not to lend money, which is not beneficial for both parties. In the setting of repeated game, reputation provide implicit motivation for contracts, the player would like to compromise by giving up short term benefits 
to choose coordinate equilibrium.

The reputation model KMRW also proves that when the payoff of one player is not known by the other, this player has the incentive to build a good reputation to exchange for long run benefits [6]. In the setting of finite game, if not all players are rational, assuming the strategy of the irrational player is called tit for tat, then one cooperative equilibrium exists.

Among the few works that study the impact of reputation on the moral hazard behavior, KMRW model is the most relevant to this study. They consider a market with a seller and a buyer in a setting that both of them are customers, but without considering demand. Considering the demand uncertainties and information asymmetry [7], we can then extend the model and answer our research question, which cannot be answered using the prior model. Thus, we specifically develop a model to investigate how the impact of the reputation to the profit of the seller.

There are mainly three forms of moral hazard [8] in C2C e-commerce, one is returned goods, and the others are deliberate cheating and shoddy goods for quality goods. As the characteristic of $\mathrm{C} 2 \mathrm{C}$ e-commerce is that the buyer could not touch the goods by himself, nor check them. For disposable shopping customers, who do not want to waste of time returning goods even though the product model or color does not meet their requirements, giving access to seller who would deregulate its product. In practice, many e-commerce websites have already regulated many items and described regulations trying to protect the benefits of buyers. But some buyers remain face the losses as they do not know full information of the model or products' attributes. In the meantime, the seller will also suffer from loss as they promise to accept returned goods unconditionally within 7 days. Furthermore, in the trade of tangible goods, the seller will present its product by photo or words, so the buyer could not get full information about the authenticity of the information and the quality of the product. For example, the biggest C2C e-commerce platform TaoBao, the seller all commit that their photos are absolutely objects photographed, but the buyer still do not have access to confirm it. It shows that information asymmetry is very common. Thirdly, the seller would sell shoddy goods for quality goods, as lack of standardized process to rating the quality of the products. Besides the preference of interest of customer influence the decision of customers. Then the seller with higher price and better products could hardly survive in the market, which is the cause of lemon market.

\section{The Model}

\subsection{Assumption}

In the setting of repeated game, we consider a market where both the sellers and the buyer are customers, which is quite popular in the real practice. There are two possible types of the seller, with the probability $p$ that he has good reputation, and $1-p$ probability that his reputation is bad. The selling price of one good is $P$ and the unit cost is $C$, the value of one good to the buyer is denoted as $V, V>P$, otherwise the buyer does not have the incentive to buy a good. Moreover, there are two actions which the seller could take no matter which type he is, to provide honest service or dishonest service.

Our model is on base of Ma (2005) that the integrity trade rate(the percentage of the honest trade among all trade), here the cost of seller with good reputation and bad reputation to take the action of being honest and dishonest is denoted as follows: $C_{S G}$ and $C_{F G}, C_{S B}$ and $C_{F B}$. "S" denotes the seller choose to be honest while "F" denotes the seller choose to be dishonest. "G" denotes the type of seller is good, while "B" denotes the type of seller is bad. As the seller of low reputation will have more management cost and more future risk, additionally, the seller with bad reputation is more familiar with cheating with the buyer, so here

Assumption 1: $0<C_{S G}<C_{S B}<C_{F B}<C_{F G}$.

The information asymmetry in C2C e-business is reflected by that the seller knows his type while the buyer lack of knowledge about it. As is shown in Figure 1, if the seller with good reputation will choose to be honest, and the buyer thinks that the seller will not cheat her, so decide to make deal with him, the revenue of the seller is: $P-C-C_{S G}$, the revenue of the buyer is $V-P$; if the buyer thinks that the seller is cheating her then decide not to make a deal with the seller, then the seller with good reputation will suffer from loss: $-C_{S G}$. Similarly, we could conclude the payoff of buyer and seller when the type of seller is bad in Figure 2.

Assumption2: Suppose the unit value of the product provided by the seller within some periods values $\pi$, which is a function of seller's service level $\alpha$, seller's real strength $\theta$ and the uncertainty in C2C e-market, that 


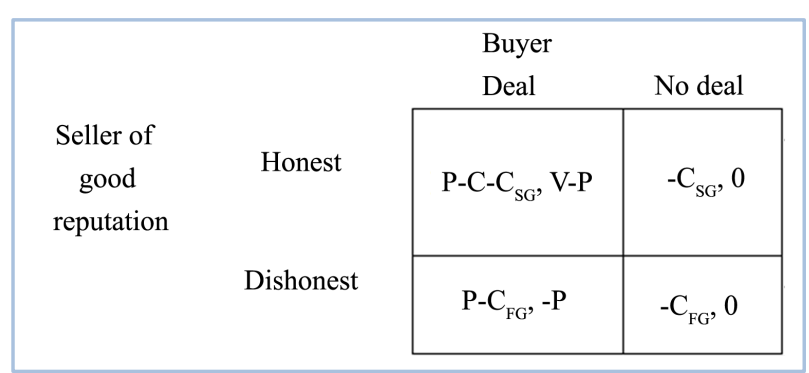

Figure 1. The payoffs of the seller with good reputation G.

\begin{tabular}{|c|c|c|c|}
\hline \multirow{3}{*}{$\begin{array}{l}\text { Seller of } \\
\text { bad } \\
\text { reputation }\end{array}$} & & $\begin{array}{l}\text { Buyer } \\
\text { Deal }\end{array}$ & No deal \\
\hline & Honest & $\mathrm{P}-\mathrm{C}-\mathrm{C}_{\mathrm{SB}}, \mathrm{V}-\mathrm{P}$ & $-\mathrm{C}_{\mathrm{SB}}, 0$ \\
\hline & Dishonest & $\mathrm{P}-\mathrm{C}_{\mathrm{FB}},-\mathrm{P}$ & $-\mathrm{C}_{\mathrm{FB}}, 0$ \\
\hline
\end{tabular}

Figure 2. The payoffs of the seller with bad reputation B.

is $\pi=k \alpha+h \theta+\mu, \alpha$ is the private information of the seller, $\pi$ is the common knowledge of both the seller and the buyer, besides $\theta$ and $\mu$ following nominal distribution, with means equal to 0 and variance equals $\sigma_{\theta}^{2}$ and $\sigma_{u}^{2}$ respectively.

Assumption3: The times that the buyer will purchase from the seller is stable to a constant $m$, then the benefits of the buyer is $w^{b}=m \pi$.

Assumption4: The sequence is as follows. Firstly the buyer will decide how many times to buy from this seller, then the seller will decide its service level.

The seller mainly benefits from the commission from purchasing timesm, that is $\beta m$, the cost of the service provided by the seller is $c(\alpha), \quad c^{\prime}(\alpha)>0, \quad c^{\prime \prime}(\alpha)>0 . \quad c(\alpha)=\left(b \alpha^{2}\right) / 2$, the revenue of the seller is $W_{s}(\alpha)=\beta m-\left(b \alpha^{2}\right) / 2$.

\section{Model Analysis}

The purpose of introducing service level of seller is to reduce the risk of buyer, to maintain its benefits of buyer and guarantee the efficiency of market. Therefore the optimal service level to maximize the total benefit in C2C market should be:

$$
\max _{\alpha}^{\pi}=m \pi+\beta m-\left(b \alpha^{2}\right) / 2 \Rightarrow \alpha=m k / b
$$

But as the first decision the buyer make is to choose the buying times from a specific seller, next the seller will decide its service level. Here $\beta m$ is a constant, as a rational person, the seller will take following actions:

$$
\begin{gathered}
\max _{a}^{\pi}=\beta m-\left(b \alpha^{2}\right) / 2 \Rightarrow \alpha^{\prime}=0 \\
\pi=\beta m-b \alpha \Rightarrow \alpha^{\prime \prime}=0
\end{gathered}
$$

In the case of single business, the seller will choose dishonest to maximize its own profits no matter what type it belongs to, and the buyer will not make a deal with seller after considering that, so this market does not exists. In the case of repeated business, the buyer will make decision on base of past shopping experience. As repeated game change the constraint mechanisms, the payoff of both parties will be different, so new equilibrium exists.

In the $1^{\text {st }}$ business, the buyer thinks that the seller belong to good reputation, so the expected payoff of buyer is $(V-P) P_{1}+(-P)\left(1-P_{1}\right)>0$, here $P_{1}$ denotes the possibility that the seller was regarded to have good reputation at first time, only when $P_{1}>P / V$, buyer will decide to make a deal with seller.

In this model, we suppose $P_{1}>P / V$, the payment at the first stage of seller, here introduce a discount rate $D$, 
which will be counted in the second trade. Specifically, if the seller is the type of B and he will cheat at the first stage, then he his payoff is as high as $P-C_{F B}$, while this also induces the buyer to confirm they type of the seller. Then at the second stage the seller will choose to be honest after considering the behavior of buyer, then $-C_{F B}<-C_{S B}$.

The total payoff of the seller is:

$$
U_{1}=\left(P-C_{F B}\right)(1+D)+\left(-C_{S B}\right)
$$

Then considering the case when the seller of bad reputation try to hide its type firstly to gain the credibility of the buyer, in order to gain more benefit in the following deal, then the strategy of the buyer is (Deal, Deal), the total pay off of the seller is:

$$
U_{2}=\left(P-C-C_{S B}\right)(1+D)+\left(P-C_{F B}\right)
$$

When the seller choose to not cheat at the first deal, then $U_{2}>U_{1}$, that is

$U_{2}-U_{1}=\left(C_{F B}-C-C_{S B}\right)(1+D)+\left(P+C_{S B}-C_{F B}\right)>0$, then $\delta=\frac{P-C}{C+C_{S B}-C_{F B}}$, here $\delta_{B}=\frac{P-C}{C+C_{S B}-C_{F B}}$ is the threshold value of seller whose type is Bad when decide which strategy to take.

Similarly, we could calculate corresponding threshold value $\delta_{G}$ of seller whose type is Good when decide which strategy to take.

From the assumption that $C_{F G}-C_{S G}>C_{F B}-C_{S B}$, we could conclude $\delta_{B}<\delta_{G}$. As long as there exists one $\delta<\delta_{B}$, whatever the type, the seller will choose to be honest in order to gain long term profit.

After the game theory analysis, we can conclude, the seller in C2C market has the incentive to maintain its reputation in order to gain more profits in the future. That also accounts for the reasons why the seller will invest more on after sellers training, improving customers service level, caring about the quality of product and the comments of finished customer, is to keep a longer seller-buyer relationship.

\section{Conclusions}

As lack of well-designed evaluation system targeted at Chinese C2C e-market, the problem of moral hazard could not be avoided or solved thoroughly. The integrity between trade partners is the basis of E-business, so it is necessary to appeal to all partners participating in E-Commerce website, both buyers and sellers and the government to work together, to push the development of evaluation system on base of reputation, to connect the benefits of sellers with its reputation, to increase the cost of irregular actions in the E-market. Generally speaking, there are following actions that can be taken to realize the function of reputation as a credible signal. Firstly, from standpoint of the online platform, it is advisable to complete the systematic rating system in the market; Secondly, from the governing of the government, it is also helpful to regulate the market by taking actions to strengthen the implementation of identity recoding and reputation supervision; Thirdly, the success of completing the evaluating system to sellers heavily depends on the efforts imposed by customers who would like to join in the activity of evaluating the ratings of sellers.

Potential extensions of our work include the study of e-commerce with one seller and many buyers, or many buyers buying the same product from many sellers. Furthermore, advanced reputation constraints could be examined for e-commerce that exhibit additional complexities (e.g., multiple echelon inventories) [9] and information asymmetry [10] in both sides could be introduced.

\section{References}

[1] Guan, X.J., Liu, J.-Z., et al. (2014) Chapter 10, Internal and External Trade, Table 10-10 Electronic Commerce Transactions. China Statistics Press, Beijing, 187.

[2] Zhang, W.Y. (1996) Game Theory and Information Economics. Shanghai Sanlian People Press, Shanghai.

[3] Dowling, G. (2004) Corporate Reputations: Should You Compete on Yours? California Management Review, 46, 19-36. http://dx.doi.org/10.2307/41166219

[4] Fama, E. (1980) Agency Problems and the Theory of the Firm. Journal of Political Economy, 88, $288-307$. http://dx.doi.org/10.1086/260866

[5] Holmstrom, B. (1999) Managerial Incentive Problem: A Dynamic Perspective. The Review of Economic Studies, 66, 169-182. 
[6] Kreps, D., Milgrom, P., Roberts, J. and Wilson, R. (1982) Rational Cooperation in the Finitely Repeat Prisoners Dilemma. Journal of Economic Theory, 27, 245-252. http://dx.doi.org/10.1016/0022-0531(82)90029-1

[7] Raz, G. (2011) Supply Chain Sourcing Under Asymmetric Information. Production and Operations Management, 20, 92-115.

[8] Corbett, C.J., Decroix, G.A. and Ha, A.Y. (2005) Optimal Shared-Savings Contracts in Supply Chains : Linear Contracts and Double Moral Hazard. European Journal of Operational Research, 163, 653-667.

[9] Ozer, O. and Raz, G. (2011) Supply Chain Sourcing Under Asymmetric Information. Production and Operations Management, 20, 92-115. http://dx.doi.org/10.1111/j.1937-5956.2010.01124.X

[10] Zhu, L. and You, J. (2011) Moral Hazard Strategy and Quality Contract Design in a Two-Echelon Supply Chain. Journal of Systems Science and Systems Engineering, 20, 70-86. http://dx.doi.org/10.1007/s11518-011-5153-2 